\title{
Pemodelan Matematika Anarkisme Demo Mahasiswa UIN Sunan Kalijaga Yogyakarta Dan Solusinya Dari Tinjauan Matematika
}

\author{
Muchammad Abrori \\ Program Studi Matematika Fakultas Sains dan Teknologi, UIN Sunan Kalijaga, Jl. Marsda Adisucipto \\ No. 1 Yogyakarta
}

Korespondensi; Email: borymuch@yahoo.com

\begin{abstract}
Abstrak
Demo anarkisme sudah menjadi hal yang umum yang sering dilihat oleh kalangan akademisi di UIN Sunan Kalijaga. Seringkali demo anarkisme ini menjadi tidak terkendali karena emosional mahasiswa yang tinggi dan emosional penjaga keamanan serta adanya ketidakpuasan mahasiswa terhadap peraturan kampus. Metode yang digunakan dalam penelitian ini dengan membuat model penyebab demo anrkisme menggunakan ordinary differential equation dan membuat simulasi dengan MATLAB. Dari pemodelan dicari titik ekuilibrium, eksistensi titik ekuilibrium dan kestabilannya. Hasil dari penelitian ini adalah pemodelan, titik ekuilibrium, kestabilannya dan simulasinya. Pemodelan yang terbentuk adalah $\frac{d 1}{d}=k_{1} x_{2}-a_{1} x_{1}+g_{1}$ dan $\frac{d_{2}}{d}=k_{2} x_{1}-a_{2} x_{2}+g_{2}$ dimana $x_{1}$ merupakan demontrasi damai, $x_{2}$ merupakan demontrasi anarkisme, $k_{1}$ merupakan itikad baik mahasiswa, $k_{1}$ merupakan emosional mahasiswa, $g_{1}$ merupakan itikad baik kampus, $g_{2}$ merupakan emosional petugas keamanan, $a_{1}$ merupakan koefisien keletihan demontrasi damai, $a_{2}$ merupakan koefisien keletihan demontrasi anarkisme. Simulasi disajikan dalam dua kasus, yaitu tidak terjadi demonstrasi anarkisme dan terjadi demonstrasi anarkisme. Simulasi yang tidak terjadi anarkisme dipengaruhi oleh itikad baik mahasiswa yang tidak mau demonstrasi anarkisme sebesar 2 dan nilai emosional mahasiswa 3. Sedangkan kasus kedua demonstrasi anarkis dipengaruhi oleh parameter itikad baik mahasiswa 0 dan nilai parameter emosional mahasiswa 4. Parameter itikad baik mahasiswa sangat menentukan terjadi atau tidak demonstrasi anarkisme mahasiswa.
\end{abstract}

Kata Kunci: Demonstrasi damai; demonstrasi anarkis; parameter emosional mahasiswa; parameter emosional petugas keamanan

\begin{abstract}
Demo anarchism has become a common thing that is often seen by academics at UIN Sunan Kalijaga. Often demo anarchism had become unmanageable because of high student emotional and emotional security guards as well as the dissatisfaction of students to campus regulations. The method used in this study to make a causal model anrkisme demo using ordinary differential equation and make the simulation with MATLAB. From modeling sought equilibrium point, the existence of the point of equilibrium and stability. Results from this study is modeling, equilibrium point, stability and simulation. Modeling is adalah $\frac{d 1}{d}=k_{1} x_{2}-a_{1} x_{1}+g_{1}$ and $\frac{d 2}{d}=k_{2} x_{1}-a_{2} x_{2}+$ $g_{2}$ where $x_{1}$ is a demonstration of peace, $x_{2}$ is a demonstration of anarchism, $k_{1}$ the good faith of students, $k_{1}$ a student emotional, $g_{1}$ a good faith campus, $g_{2}$ is emotional security officer, $a_{1}$ a peaceful demonstration coefficient of fatigue, exhaustion coefficient demonstration $a_{2}$ is anarchism. Simulations are presented in two cases, that is not a demonstration of anarchism and anarchist demonstrations. The simulations do not happen anarchism influenced by the good faith of students who do not want a demonstration of anarchism by 2 and 3 . While the student emotional value both cases anarchist demonstration of good faith is affected by the parameters and parameter values student 0 emotional student student 4 . Parameters good faith is crucial occur or not anarchism student demonstrations.
\end{abstract}

Keywords: Peaceful demonstrations; anarchist demonstration; emotional parameters of the student; emotional parameter security officer 


\section{Pendahuluan}

Anarkisme mahasiswa kini seolah-olah menjadi bagian tidak terpisahkan dari demonstrasi-demonstrasi mahasiswa, dan telah menimbulkan korban bukan hanya jiwa manusia, tetapi juga harta benda [1]. Kerugian fasilitas umum seperti kantor pemerintah, kampus, dan lain-lain yang sebetulnya sangat penting untuk meningkatkan kemajuan dan kesejahteraan warga kampus pun tidak terhitung jumlahnya. Mengapa demonstrasi mahasiswa bisa mengarah pada munculnya perilaku anarkis? Apakah tindakan anarkis tersebut merupakan bagian dari demonstrasi itu sendiri, dengan kata lain sesuatu yang memang direncanakan bersama dengan rencana demonstrasi? Ataukah, perilaku anarkis tersebut tidak direncanakan sebelumnya, melainkan muncul karena situasi di lapangan memicu munculnya hal tersebut, seperti misalnya perilaku aparat yang saat itu bertugas di lokasi demonstrasi? Manfaat apakah yang diharapkan oleh para pelaku demonstrasi melalui tindakan anarkis yang dilakukannya?

Oleh karena itu, perlu dirintis upaya untuk mengembalikan citra dan peran mahasiswa sebagai pelopor perubahan sosial dengan cara-cara yang kritis dan mengedepankan semangat demokratis. Guna melangkah ke tahap itu, penelitian perlu dilakukan untuk melihat faktor-faktor yang melatarbelakangi munculnya anarkisme dalam demonstrasi mahasiswa dewasa ini.

Pendekatan kuantitatif yang digunakan dalam penelitian ini adalah berupa survey, untuk kemudian dibuat deskripsi dan penjelasan statistik mengenai keenam variabel yang diduga berkaitan dengan munculnya anarkisme dalam demonstrasi mahasiswa agar dapat diketahui kontribusi atau pengaruh keenam variabel tersebut terhadap variabel demonstrasi anarkis. Pendekatan kualitatif yang digunakan dalam penelitian ini berfungsi untuk menunjang dan memperkaya temuan pendekatan kuantitatif. Pengambilan data dalam pendekatan kualitatif dilakukan melalui focus group discussion (FGD). Terdapat sejumlah faktor pendorong keterlibatan seorang mahasiswa dalam suatu demonstrasi, meliputi faktor personal dan faktor kontekstual. Faktor personal yang membedakan individu bervariasi satu sama lain dalam hal motif. Faktor personal yang membedakan kelompok (Jakarta-Makasar dan antar kampus) adalah budaya dan ideologi. Dalam penelitian ini adalah budaya syiri pada kelompok Makassar dan ideologi tertentu pada salah satu universitas. Peran kekuatan eksternal dalam isu-isu tertentu, misalnya menyangkut kebijakan politik tertentu, ada kekuatan eksternal yang ikut menumpangi demonstrasi mahasiswa. Kekuatan eksternal dimaksud adalah partai politik dan ormas, yang mendapatkan keuntungan tertentu jika suatu isu terangkat ke hadapan publik.

\section{Pembahasan}

\section{Data}

Data berikut diambil selain bersumber dari mahasiswa, pejabat, karyawan dan petugas keamanan. Berikut adalah pernyataan parameter untuk pengambilan data.

Petunjuk: Mohon dapat memilih alternatif jawaban dengan cara memberi tanda check () pada kolom yang tersedia ( $4=$ sangat setuju; $3=$ setuju; 2 = kurang setuju; $1=$ tidak setuju).

\section{Pernyataan parameter itikad baik mahasiswa}

\begin{tabular}{llll} 
Point & \\
\hline 1 & 2 & 3 & 4
\end{tabular}

\footnotetext{
1. Demontrasi damai dilakukan untuk mendapatkan simpati publik

2. Simpati publik diperlukan supaya orang mau mendukung terhadap materi demonstrasi yang disampaikan

3. Mahasiswa adalah penerus bangsa sehingga sehingga harus mampu memberi contoh yang baik

4. Demonstran ingin mencari win-win solution

5. Mahasiswa merupakan kader intelektual sehingga mereka tidak pantas melakukan kekerasan

6. Demonstrasi secara damai di lingkungan kampus lebih efektif daripada dengan kekerasan

7. Mahasiswa demonstran menginginkan dialog dengan pimpinan universitas

8. Adanya itikad baik untuk turut berperan serta dalam perubahan dan kemajuan

9. Mahasiswa merupakan agen perubahan sosial

10. Mahasiswa menyadari bahwa apabila melakukan hal-hal yang negatif akan menjadi sorotan masyarakat
} 


\section{Pernyataan parameter emosional mahasiswa}

Point

1. Sikap para demonstran yang menganggap pendapat mereka paling benar dan harus dituruti.

2. Suasana panas, sesak dan penat akan membuat para demonstran cenderung mudah terpancing emosinya, sedikit saja ada provokasi dari luar pastilah kerusakan akan terjadi.

3. Jumlah demonstran yang banyak membuat situasi sangat sulit untuk dikontrol dan dikendalikan.

4. Jumlah aparat juga lebih sedikit dari pada para demonstran.

5. Solidaritas yang tinggi antara para anggota demonstran.

6. Orasi dari sesama demonstran yang provokatif.

7. Energi anak muda yang masih sangat besar tetapi tidak tersalurkan dengan baik.

8. Sebagai ajang untuk belajar berpolitik praktis.

9. Sikap anak muda yang tidak mau mengalah dan tidak mengenal kata kompromi.

10. Terlalu bersemangat bertindak sebagai agen perubahan (agent of change).

11. Adanya perasaan sebagai kaum tertindas yang sedang melawan penguasa (birokrat kampus).

12. Adanya keinginan untuk ikut mengatur kehidupan di kampus.

13. UIN Sunan Kalijaga diidentikkan sebagai kampus perjuangan. Berjuang bilamana perlu menggunakan kekerasan.

14. Meneruskan tradisi demonstrasi dari kakak-kakak angkatan mereka.

15. Indoktrinasi dari kakak-kakak angkatan yang dilakukan sejak dini (semester 1) bahwa penguasa (birokrat kampus harus dilawan).

\section{Pernyataan parameter itikad baik kampus}

$1 \quad 2 \quad 3 \quad 4$

4




\section{Pernyataan parameter koefisien keletihan demontrasi damai}

Point

$\begin{array}{llll}1 & 2 & 3 & 4\end{array}$

1. Orasi yang berlebihan bisa memancing mahasiswa bertindak anarkhis

2. Demo yang dilakukan berjam-jam sampai letih bisa memancing emosional mahasiswa

3. Petugas yang keletihan akan mudah terpacing emosinya

4. Demonstrasi damai bisa disusupi provokator sehingga menjadi anarkhis

5. Demo yang tidak didengar mengakibatkan mahasiswa frustasi

6. Keletihan menimbulkan frustasi bagi mahasiswa demonstran

7. Demo yang tidak didukung logistik bisa mempercepat keletihan

8. Cuaca yang panas di Yogyakarta mempercepat terjadinya keletihan demonstran

9. Pimpinan kampus yang tidak menanggapi atau menemui demonstran membuat demonstran merasa letih

10. Demonstarasi yang dilakukan sampai berhari-hari membuat letih para demonstran

\section{Pembentukan Model}

Model ini merupakan model pengembangan Model Richarson [2], [3]. Model Richarson merupakan model peperangan dua negara atau beberapa negara menyerang suatu negara. Model ini memperhitungkan nilai itikad baik kampus, nilai itikad baik mahasiswa, emosional petugas keamanan dan emosional mahasiswa.

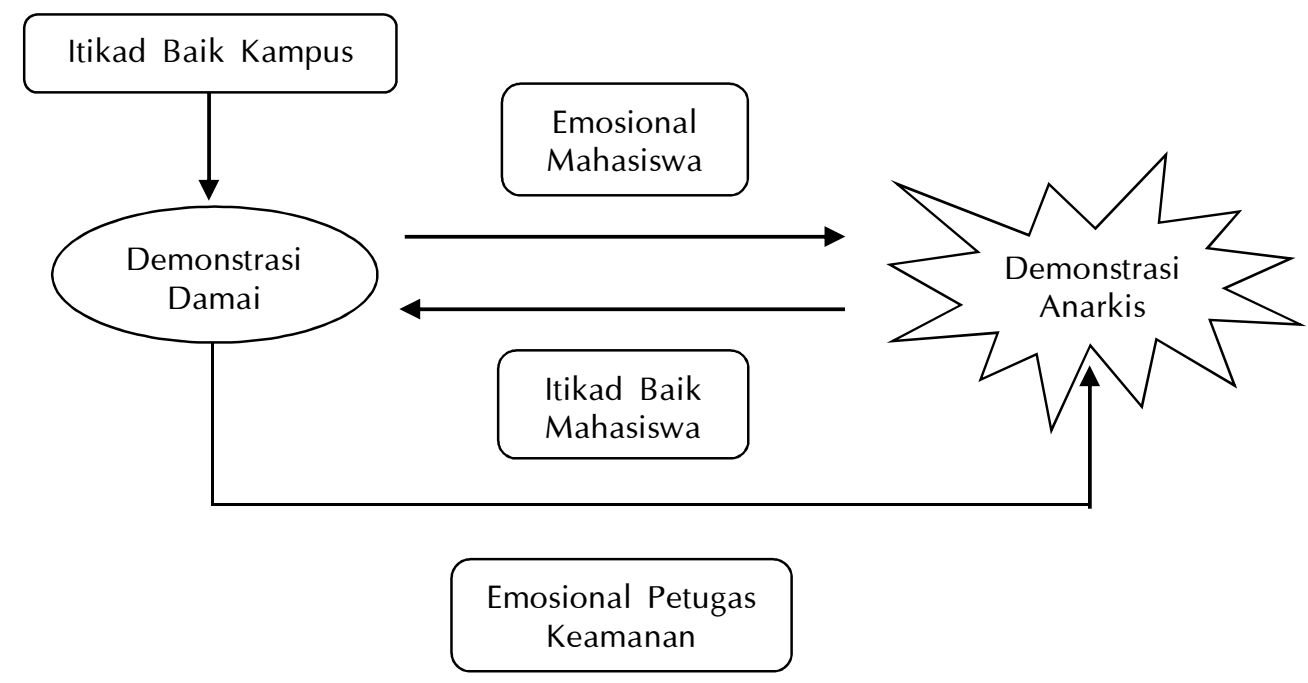

Gambar 1 Faktor-faktor penyebab demontrasi anarkime.

Model ini mengasumsikan bahwa penyebab demonstrasi anarkisme dari data dijadikan satu yaitu emosional mahasiswa. Model matematika dapat digambarkan pada Gambar 2 berikut.

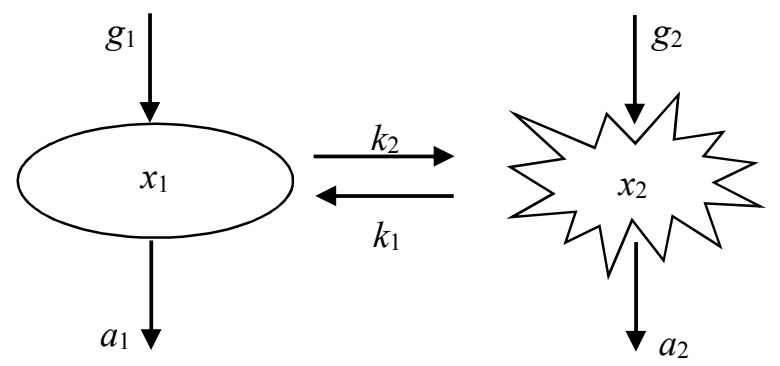

dimana:
$x_{1}=$ Demontrasi damai.
$x_{2}=$ Demontrasi anarkisme.
$k_{1}=$ Itikad baik mahasiswa.
$k_{2}=$ Emosional mahasiswa.
$g_{1}=$ Itikad baik kampus.
$g_{2}=$ Emosional petugas keamanan.
$a_{1}=$ Koefisien keletihan demontrasi damai.
$a_{2}=$ Koefisien keletihan demontrasi anarkisme.

Gambar 2 Model sistem yang dibentuk dari demo anarkisme. 
Sistem persamaan matematika yang dibentuk dari pemodelan ini adalah ordinary differential equation [4], [5], [6]. Model matematikanya adalah:

$$
\begin{aligned}
& \frac{d_{1}}{d}=k_{1} x_{2}-a_{1} x_{1}+g_{1} \\
& \frac{d_{2}}{d}=k_{2} x_{1}-a_{2} x_{2}+g_{2}
\end{aligned}
$$

dengan nilai semua parameter antara 0 sampai dengan 4.

\section{Titik Kesetimbangan}

Kondisi keseimbangan menyatakan demonstrasi anarkisme akan berakhir. Kondisi kesembangan terjadi ketika $\frac{d_{1}}{d}=\frac{d_{2}}{d}=0$. Ttitik kesetimbangannya adalah

$$
\hat{x}_{1}=\frac{k_{1} g_{1}+a_{2} g_{1}}{a_{1} a_{2}-k_{1} k_{2}} \text { dan } \hat{x}_{2}=\frac{k_{2} g_{1}+a_{1} g_{2}}{a_{1} a_{2}-k_{1} k_{2}}
$$

dengan menetapkan $a_{1} a_{2}-k_{1} k_{2} \neq 0$.

\section{Eksistensi Titik Ekuilibrium}

Titik ekuilibrum ada jika $\hat{x}_{1}=\frac{k_{1} g_{1}+a_{2} g_{1}}{a_{1} a_{2}+k_{1} k_{2}}$ dan $\hat{x}_{2}=\frac{k_{2} g_{1}+a_{1} g_{2}}{a_{1} a_{2}+k_{1} k_{2}}$ positif, sehingga nilai tersebut ada jika $a_{1} a_{2}-k_{1} k_{2}>0$ atau $a_{1} a_{2}>k_{1} k_{2}$. Dengan kalimat dapat ditulis bahwa perkalian koefisien keletihan demonstrasi damai dengan koefisien keletihan demontrasi anarkis lebih besar daripada perkalian koefisien itikad baik mahasiswa dengan koefisien emosional mahasiswa. Nilai $a_{1} a_{2}$ lebih besar $k_{1} k_{2}$ karena ketika demo itu sudah berlangsung berjam-jam maka faktor keletihan lebih dominan terhadap faktor-faktor penyebab demo, sehingga titik ekuilibrium ada.

\section{Analisis Kestabilan Titik Ekuilibrium}

Misalkan

$$
\begin{aligned}
& f_{1}=\frac{d_{1}}{d}=k_{1} x_{2}-a_{1} x_{1}+g_{1} \\
& f_{2}=\frac{d_{2}}{d}=k_{2} x_{1}-a_{2} x_{2}+g_{2}
\end{aligned}
$$

Matrik Jacobian adalah,

$$
J\left(x_{1}, x_{2}\right)=\left[\begin{array}{ll}
\frac{d_{1}}{d x_{1}} & \frac{d_{1}}{d x_{2}} \\
\frac{d_{2}}{d x_{1}} & \frac{d_{2}}{d x_{2}}
\end{array}\right]=\left[\begin{array}{cc}
-a_{1} & k_{1} \\
k_{2} & -a_{2}
\end{array}\right]
$$

Matrik Jacobian di titik ekuilibrium adalah $J\left(\hat{x}_{1}, \hat{x}_{2}\right)=\left[\begin{array}{cc}-a_{1} & k_{1} \\ k_{2} & -a_{2}\end{array}\right]$. Persamaan karakteristiknya adalah $\left|J\left(\hat{x}_{1}, \hat{x}_{2}\right)-\lambda\right|=0$ dimana $l=\left[\begin{array}{ll}1 & 0 \\ 0 & 1\end{array}\right]$, sehingga Persamaan karakteris diperoleh $\lambda^{2}+$ $\left(a_{1}+a_{2}\right) \lambda+a_{1} a_{2}-k_{1} k_{2}=0$. Nilai eigennya adalah $\lambda_{1,2}=\frac{-\left(a_{1}+a_{2}\right) \pm \sqrt{\left(a_{1}+a_{2}\right)^{2}+4 k_{1} k_{2}}}{2}$. Menurut kriteria Routh Hurwitz [7] karena $\lambda_{1,2}=\frac{-\left(a_{1}+a_{2}\right)+\sqrt{\left(a_{1}+a_{2}\right)^{2}+4 k_{1} k_{2}}}{2}>0$ dan $\lambda_{1,2}=\frac{-\left(a_{1}+a_{2}\right)-\sqrt{\left(a_{1}+a_{2}\right)^{2}+4 k_{1} k_{2}}}{2}<0$. Karena salah satu nilai eigen lebih besar dari nol maka titik ekuilibium ini tidak stabil. Tafsiran di lapangan ketika terjadi demonstrasi anarkisme maka anarkisme bisa terjadi sewaktu-waktu karena tidak stabil titik ekuilibrium ini. 


\section{Simulasi}

Dalam simulasi ini akan disajikan dua kasus.

Kasus I: Tidak terjadi demonstrasi anarkisme.

Kasus II: Terjadi demonstrasi anarkisme.

Tabel 1 Nilai-nilai parameter model demonstrasi tetapi tidak anarkis dan data yang dipakai merupakan data primer.

\begin{tabular}{lcc}
\hline No. & Parameter & Nilai \\
\hline 1. & $k_{1}$ & 2 \\
2. & $k_{2}$ & 3 \\
3. & $a_{1}$ & 1 \\
4. & $a_{2}$ & 2 \\
5. & $g_{1}$ & 2 \\
6. & $g_{2}$ & 3 \\
\hline
\end{tabular}

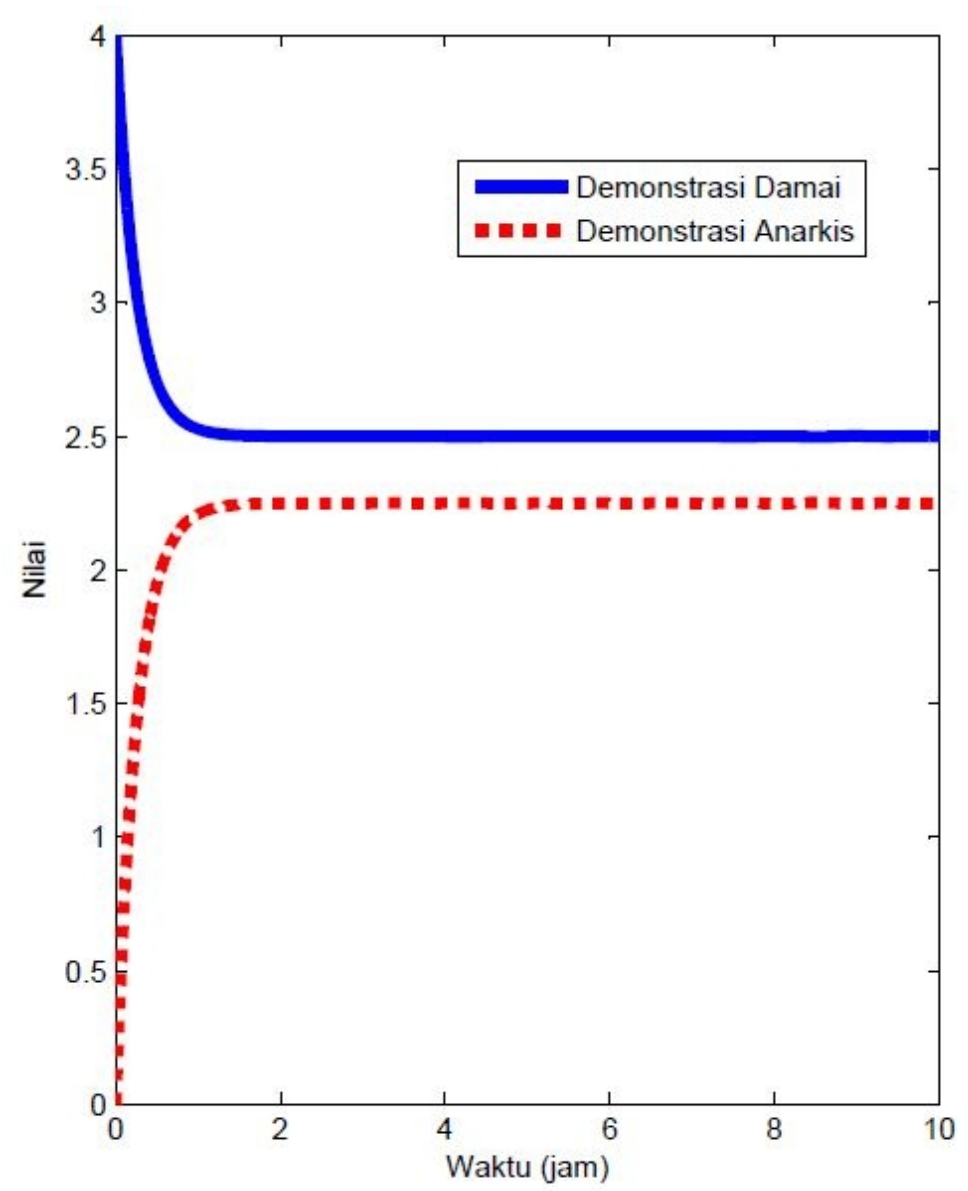

Gambar 3 Terjadi demonstrasi tetapi tidak anarkis (demonstrasi damai).

Pada Gambar 3 merupakan simulasi ketika demontrasi UIN Sunan Kalijaga terjadi dan berlangsung demonstrasi damai. Model ini tidak terjadi anarkisme karena tidak berpotongan antara demontrasi damai (garis biru) dan demonstrasi anarkisme (garis merah, garis putus-putus). Pada jam pertama nilai demonstrasi damai terjadi penurunan dengan sangat cepat, sebaliknya nilai demiontrasi anarkisme sangat cepat kenaikannya. Jika mahasiswa dan petugas keamanan tidak menahan diri maka nilai demonstrasi damai akan turun dan nilai demontrasi anarkis akan naik, sehingga garis tersebut akan berpotongan. Hal ini berakibat akan terjadi demontrasi anarkis. 
Tabel 2 Nilai-nilai parameter model demontrasi anarkis dan data yang dipakai merupakan data primer.

\begin{tabular}{lcc}
\hline No. & Parameter & Nilai \\
\hline 1. & $k_{1}$ & 0 \\
2. & $k_{2}$ & 4 \\
3. & $a_{1}$ & 0,39 \\
4. & $a_{2}$ & 0 \\
5. & $g_{1}$ & 0 \\
6. & $g_{2}$ & 4 \\
\hline
\end{tabular}

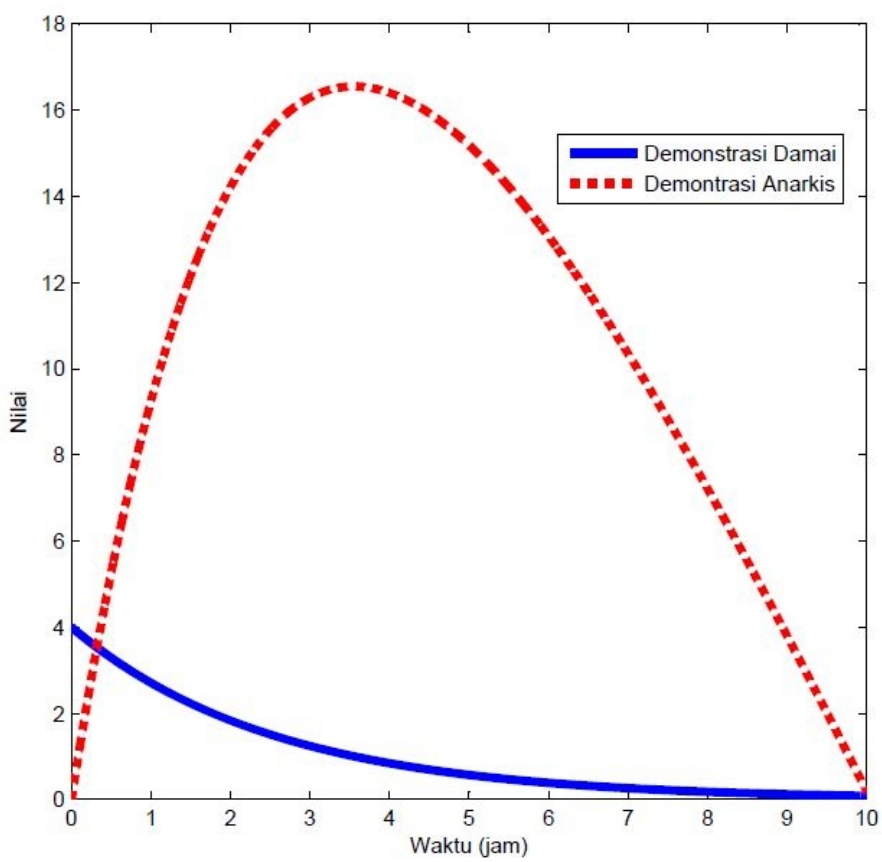

Gambar 4 Terjadi demonstrasi anarkis.

Pada Gambar 4 merupakan demontrasi anarkisme. Pada jam pertama langsung terjadi demonstrasi anarkis. Penurunan nilai demontrasi damai stabil sampai waktu 10 jam demontrasi dan nilai demontrasi damai adalah nol pada 10 jam demontrasi. Sedangkan nilai demontrasi anarkis naik begitu cepat pada 3 jam pertama naik, setelah itu turun dengan stabil. Pada 10 jam pertama nilai demontrasi damai dan nilai demonstrasi anarkis bernilai nol. Hal ini karena faktor keletihan mahasiswa menjadikan nilai demontrasi damai dan nilai demontrasi anarkis menjadi nol.

Terjadinya demonstrasi damai maupun demonstrasi anarkis dipengaruhi oleh beberapa faktor, yaitu parameter-parameter yang dimodelkan di sini. Parameter demonstrasi damai dan demonstrasi anarkime sangat mencolok perbedaannya. Pada Tabel 3 berikut dapat dibandingkan.

Tabel 3 Perbandingan nilai-nilai parameter model demontrasi damai dan demonstrasi anarkis.

\begin{tabular}{cccc}
\hline \multirow{2}{*}{ No. } & \multirow{2}{*}{ Parameter } & \multicolumn{2}{c}{ Nilai } \\
\cline { 3 - 4 } & & Demonstrasi Damai & Demonstrasi Anarkis \\
\hline 1. & $k_{1}$ & 2 & 0 \\
2. & $k_{2}$ & 3 & 4 \\
3. & $a_{1}$ & 1 & 0,39 \\
4. & $a_{2}$ & 2 & 0 \\
5. & $g_{1}$ & 2 & 0 \\
6. & $g_{2}$ & 3 & 4 \\
\hline
\end{tabular}


Dari Tabel 3 di atas dapat dilihat bahwa nilai parameter itikad baik mahasiswa, itikad baik kampus, dan faktor keletihan demonstrasi damai yang membedakan demontrasi damai dan demonstrasi anarkis. Parameter-parameter yang baik berkurang menjadikan demonstrasi anarkis.

\section{Kesimpulan}

a. Pemodelan yang terbentuk adalah $\frac{d_{1}}{d}=k_{1} x_{2}-a_{1} x_{1}+g_{1}$ dan $\frac{d_{2}}{d}=k_{2} x_{1}-a_{2} x_{2}+g_{2}$ dimana $x_{1}$ merupakan demontrasi damai, $x_{2}$ merupakan demontrasi anarkisme, $k_{1}$ merupakan Itikad baik mahasiswa, $k_{2}$ merupakan emosional mahasiswa, $g_{1}$ merupakan Itikad baik kampus, $g_{2}$ merupakan emosional petugas keamanan, $a_{1}$ merupakan koefisien keletihan demontrasi damai, $a_{2}$ merupakan koefisien keletihan demontrasi anarkisme.

b. Titik ekuilibrum adalah $\hat{x}_{1}=\frac{k_{1} g_{1}+a_{2} g_{1}}{a_{1} a_{2}-k_{1} k_{2}}$ dan $\hat{x}_{2}=\frac{k_{2} g_{1}+a_{1} g_{2}}{a_{1} a_{2}-k_{1} k_{2}}$ dengan $a_{1} a_{2}>k_{1} k_{2}$.

c. Analisis kestabilan titik ekuilibrium ditentukan dengan nilai eigen yaitu $\lambda_{1,2}=\frac{-\left(a_{1}+a_{2}\right)-\sqrt{\left(a_{1}+a_{2}\right)^{2}+4 k_{1} k_{2}}}{2}$ dan karena salah satu nilai eigen lebih besar dari nol maka titik ekuilibium ini tidak stabil atau anarkisme bisa terjadi sewaktu-waktu karena tidak stabilnya titik ekuilibrium ini.

d. Simulasi disajikan dalam dua kasus, yaitu tidak terjadi demonstrasi anarkisme dan terjadi demonstrasi anarkisme. Simulasi yang tidak terjadi anarkisme dipengaruhi oleh itikad baik mahasiswa yang tidak mau demonstrasi anarkisme sebesar 2 dan nilai emosional mahasiswa 3. Sedangkan kasus kedua demonstrasi anarkis dipengaruhi oleh parameter itikad baik mahasiswa 0 dan nilai parameter emosional mahasiswa 4. Hal ini sangat jelas berbeda antara demonstrasi damai dan demonstrasi anarkisme dilihat dari parameter. Parameter itikad baik mahasiswa sangat menentukan terjadi atau tidak demonstrasi anarkisme mahasiswa.

\section{Referensi}

[1] Balya, 2013, Skripsi: Mahasiswa dan Kekerasan (Studi terhadap Demonstrasi UIN Sunan Kalijaga 2008-2012), UIN Sunan Kalijaga. Yogyakarta.

[2] Richardson, L. F., 1960a, Arms and Insecurity: A Mathematical Study of the Causes and Origins of War, Pittsburgh: Boxwood 1960.

[3] Richardson, L. F., 1960b, Statistics of Deadly Quarre/s. (Quincy Wright, C.C. Lienau, eds.) Pittsburgh: Boxwood Press 1960.

[4] Sugiyanto, 2011, Persamaan Diferensial Biasa, Suka Press: Yogyakarta.

[5] Kreyszig, Erwin, 1993, Advanced Engineering Mathematics, Sixth Edition, John Wiley \& Son, Inc, New York.

[6] Ayres, Frank J. R., 1999, Theory and Problem of Differential equation, first Edition, Schouns Outline Series, Mc Graw Hill International Book Company, Singapore.

[7] Olsder, G. J., 1994, Mathematical System Theory, First Edition, T. U. Delf: Netherlands. 